\title{
Univ.-Prof. Dr. Heinz Schenk - 80 Jahre
}

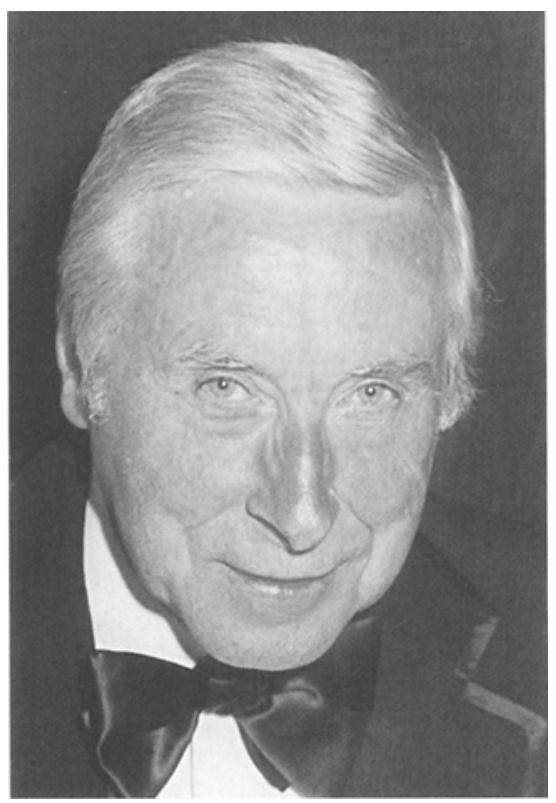

Prof. Dr. Heinz Schenk wurde am 17. Oktober 1925 als Sohn des Dr. Karl Schenk, Lehrer und Hauptschuldirektor, und seiner Gattin Louise in Wien geboren. Nach Absolvierung des Real-Gymnasiums III in Wien wurde er vorzeitig zum Wehrdienst einberufen und verbrachte seine Militärzeit in einem Gebirgsjägerregiment. Er machte den Italienfeldzug mit. Am 1. April 1945 wurde er zum Leutnant befördert. Es folgte der Rückzug aus dem Raum Neapel bis zur Kapitulation der Südarmee im April 1945. Hernach konnte er sich nach Fulpmes in Tirol durchschlagen und wurde am 2. Mai 1945 aus dem Heer entlassen, was in den Wirren der letzten Kriegstage recht selten geschah.

\section{Kongressberichte}

\section{Herbst-Symposium der Vereinigung kontaktlin- senanpassender Augenärzte Österreichs}

Am 15. Oktober 2005 fand in Salzburg die alljährliche Tagung der Vereinigung kontaktlinsenanpassender Augenärzte statt. Vor einem Publikum von gut 100 Augenärzten/ -ärztinnen referierten Spezialisten aus dem In- und Ausland über Themen wie „Verband-Kontaktlinsen im Spezialeinsatz", Kontaktlinsen für Alterssichtigkeit (Presbyopie), neue Kontaktlinsen-Materialien. Auch anderen medizinischen Bereichen, wie „Patientenorientierte Kommunikation“ und Ver-
1954 ehelichte Dr. Schenk seine Gattin Friederike geb. Hitzinger, 1964 wurde sein Sohn Wolfgang geboren.

Im Oktober 1945 begann Dr. Schenk das Medizinstudium in Wien und promovierte am 15. Juni 1950 zum Dr. univ. med. an der Alma Mater Rudolfina. Bereits im Juli 1950 trat er in die I. Universitäts-Augenklinik unter Prof. Pillat ein und wurde 1954 klinischer Assistent (= Oberarzt). 1961 habilitierte Dr. Schenk und 1975 wurde er zum a.o. Univ.Professor ernannt. Jahrelang leitete Prof. Schenk an der I. Universitäts-Augenklinik die Station mit der Kinderabteilung. Er war als ausgezeichneter Diagnostiker bekannt, und wir jungen Kollegen haben von ihm sehr viel gelernt. Nach der Emeritierung Prof. Pillats folgte 1964 Prof. Hruby als Klinikchef. Nach dessen Emeritierung 1981 wurde Prof. Schenk zum supplierenden Leiter der Klinik für zwei Jahre ernannt. Nach über 40-jähriger Tätigkeit an der I. Universitäts-Augenklinik trat er am 31. Dezember 1990 in den Ruhestand.

Neben zahlreichen Vorträgen vor der ÖOG, der DOG und der Ophthalmologischen Gesellschaft in Wien, publizierte Prof. Schenk 76 wissenschaftliche Arbeiten, etwa zwei Drittel davon als Alleinautor. Neben dieser klinischen und wissenschaftlichen Tätigkeit führte Prof. Schenk seine Privatpraxis und war als exzellenter Operateur bekannt. Von 1968 bis 1995 gehörte Prof. Schenk dem Vorstand der Österreichischen Ophthalmologischen Gesellschaft als Kassier an. In diese Zeit fällt auch das Erbe von Frau Dr. A. Rabensteiner, welches Prof. Schenk vorausschauend verstand, gewinnbringend anzulegen.

Im Namen der österreichischen Augenärzteschaft, im Namen der ÖOG und im eigenen Namen gratuliere ich Herrn Prof. Dr. Heinz Schenk herzlich zu seinem 80. Geburtstag und wünsche ihm noch viele gesunde und zufriedene Jahre.

Prim. Prof. Dr. Paul Drobec, Wien kehrsophthalmologie wurde Raum gegeben. Rege Diskussion nach den Vorträgen zeigte das große Interesse der Teilnehmer an diesen und weiteren wichtigen Problemkreisen der augenärztlichen Tätigkeit und des Praxisalltages. Eine übersichtliche Industrieausstellung ermöglichte den Teilnehmern, Neues und Bewährtes aus nächster Nähe zu beurteilen. Parallel dazu wurde ein Assistentinnen-Seminar abgehalten, das ebenso gut besucht war.

Das nächste Symposium wird am 14. Oktober 2006 - ebenfalls in Salzburg - stattfinden. 